\title{
Assessing Health and Safety Requirements in Construction Contracts in Botswana
}

\author{
Erastus Mwanaumo, ${ }^{*}$ Wellington Didibhuku Thwala, Jan-Harm Pretorius \\ University of Johannesburg, Johannesburg, South Africa \\ *didibhukut@uj.ac.za
}

\begin{abstract}
The purpose of this study was to investigate the effect of contractor selection andrequirements on Health and Safety compliance in Botswana. Literature was reviewed, a questionnairesurvey was conducted and the statistical analysis undertaken. According to Murie (2007), one of the weaknesses of adopting traditional procurement approach is that the successful tender will frequently be the one that, among others, does not provide H\&S protective equipment or have insurance coverage for accidents, and has the largest proportion of informal workers, who are not covered in practice by any legal or social protection. The study has provided usefulinformation involving key stakeholders involvement in $\mathrm{H} \& \mathrm{~S}$ performance in constructionindustry. The traditional method could thus impede on Health and Safety management from project preplanningthrough to construction on site.
\end{abstract}

Keywords: Health and Safety, Construction, Contracts, Stakeholders

\section{Introduction}

Traditional method of procurement is importance in understanding the intricacies of various procurement methods and contracts available for the construction industry. According to van Rijn (2005), it is only by analysing the relationship between the contracting parties is possible to understand the problems that other forms of procurement try to resolve. At the heart of the traditional contract lies the conflict between design on the one hand and workmanship on the other. The conflict is complicated further by the need to allocate rights to third parties.In the traditional method of procurement, the client contracts with an architect or engineer to carry out the design. The architect or engineer, acting as the agent of the employer, supervises the construction of that design. The contractor enters into a contract with the employer to build that design. According to van Rijn (2005), there is no guarantee given by the client to the contractor that the design by the architects or engineers can be built. In carrying out the work, the contractor employs both subcontractors and suppliers of services, goods and equipment. Contractually, the appointed subcontractor could be classified as domestic or nominated. Out of the relationship between these parties arises the issue of privity of contract: the basic rule that only parties to a contract can enforce the contract (Van Rijn, 2005).

\section{Literature Review}

Kumaraswamy and Dulaimi (2001) claim that the traditional procurement method is problematic since it is incapable of managing complex multiple-goal, multidisciplinary and multi-participant scenarios. The authors argue that the cause is the procurement method's non-holistic approach. According to Rwelamila, Talukhaba and Ngowi (2000), traditional procurement approach and its respective contract arrangements are used merely because the clients and project consultants do not seem to consider the issue of selecting an appropriate procurement system. They argue that this procurement method provides a poor relationship management system that does not reflect sustainability parameters. This is because contracts are awarded on the basis of price, while tenders are based on incomplete designs (Rwelamila et al., 2000).

Impact of procurement systems and contractual relationships on health and safety: Any procurement method leads to establishment of contractual relations. Contractual relations in turn establish the contractual specifications, including that of H\&S. However, the traditional procurement method contractual relationships are seen by scholars as impacting negatively on the construction H\&S. Smallwood (1996), for instance, contends that contractors who apportion adequate resources to H\&S can be disadvantaged in terms of market competitiveness by those who do not when the traditional method of procurement is adopted. Hislop (1999) further adds that even though there is an increase in supply chain integration, coordination, communication and collaboration, a typical model for H\&S management 
is both non-existent and unnecessary. This argument is based on the premise that all organisations and projects are distinctly structured and that one generic model cannot be both practical and effective.

The Egan report in the UK, captured by Winch (2000), suggests that entrance of bad competitors needed to be barred. To do that, the procurement method of partnering was advocated as one way in which barriers could be erected. This suggests moving from traditional methods to adoption of the new partnering method. This shift could be difficult to achieve in most countries, particularly in African developing nations, in the short term. As such, Smallwood (2004) recommends that the existing popular procurement method (the Traditional method) should be utilised to achieve good H\&S performance of the industry. One way is to complement the pre-qualification selection process of main contractors by adding H\&S standards to ensure that only H\&S-conscious contractors are selected (Smallwood 2004). This approach should be followed during the selection and appointment of the designers.In order to protect the contractor on site especially when subcontractors are to be employed and no clear H\&S specifications were laid down during the procurement process, Kartam et al. (2000) suggest that contractual specifications of H\&S must establish specific guidelines in order to control anticipated hazards by naming the person responsible for overseeing the contractor's performance. These guidelines should require the contractors to prepare and submit an acceptable project hazard prevention plan that defines supervisory and employee H\&S training, identifies specific published H\&S standards and hazard prevention requirements, and lists restriction to protect those whose past performances demonstrate care, competence and good H\&S work.

\section{Methodology}

The purpose of this study was to investigate the effect of contractor selection and requirements on $\mathrm{H} \& \mathrm{~S}$ compliance. The sample of 150 construction industry practitioners and main clients were targeted. These key construction industry stakeholders were based in Gaborone, the main town of Botswana. Of the 150 distributed questionnaires, 96 questionnaires were collected and a total of 91 questionnaires were accepted. The exercise to allocated variables and label values to variables was performed. Data was verified by performing frequency analysis. Missing values were then identified. Upon commencement of investigations, various statistical methods were adopted in order to Perform Reliability analysis and calculate the factors. This exercise was followed by performing factor analysis using the Principal Component extraction and the Varimax Rotation as well as correlation and relationship between the two factors / indexes. Therefore a total response rate of $61 \%$ was achieved based on the useable questionnaires.The majority of the stakeholders either sponsored or were engaged in buildingconstruction type of project represented by $84 \%$. Only $15 \%$ of the respondents undertook civil engineering type of projects. At the time of conducting the research, this was a true reflection of the nature of projects in Botswana construction industry. The remaining one per cent (1\%) represented stakeholders that were involved in specialist engineering works doing work within the construction sector such as mechanical engineering (for instance those who HVAC) and Construction Mining activities.

The contractors represented $34 \%$ of usable respondents. These contractors were classified into three categories. The small category was represented by grade OC and A on the Public Procurement Asset Disposal Board (PPADB). The medium category was represented by grade B and C, while the larger category of contractors is registered in grades $\mathrm{D}$ and $\mathrm{E}$. The target for each of the contractor categories was to get a representation from the top management in the head office and top management on a specific project site. A combined total for both head office and project site management was recorded. A total of $23 \%$ of contractor respondents were in the smaller categories, $44 \%$ were from the medium category and 33\% represented the larger categories of contractor respondents. The smaller percentage of responses from smaller category is attributed to the fact that the majority of the top management of these contractors are the same top management of the project site. Therefore the number of respondents could have been double the given percentage reflecting a significant contribution to the study.

\section{Results}

Health and safety requirements in contracts: Thirteen contract H\&S requirements and the accompanying specifications factors were extracted from international research (McDonald and Hrymak, 2002; Murie, 2007) and from the statutory documents on which stakeholders rely in the Botswana construction Industry viz. Factories Act and the workmen compensation Act. In order to assess the importance of having these in the contract documents a factor analysis using the Principal component 
extraction with Varimax (orthogonal) rotation was. The focus was to establish whether $H \& S$ is a requirement in the contract prepared by the client to be entered into by the contractor. Each factor was labelled in accordance with the common thread that connects the set of individual items loaded on it as indicated in Table 1.

\section{Table 1: Factor loading for the two identified Factors}

\begin{tabular}{lll}
\hline Requirements in Contracts & Factor1 & Factor2 \\
\hline Contractor must place at least one full-time H\&S representative on the project. & 0.649443 & 0.599046 \\
Contractor must implement a drug-testing program. & 0.104879 & 0.869221 \\
Contractor must provide health and safety orientation to all employees on-site. & 0.617189 & 0.613516 \\
Contractor must record, investigate, and report near misses to the owner & 0.624780 & 0.708655 \\
Contractor must submit an H\&S policy signed by its CEO. & 0.285585 & 0.778186 \\
Contractor must conduct pre-tender, award, and construction meetings with & 0.938363 & 0.169201 \\
subcontractors. & & \\
Contractor must comply with the district and national health and safety & 0.926445 & 0.302100 \\
regulations. & 0.814677 & 0.419816 \\
Contractor must submit the résumés of key H\&S personnel for client approval. & 0.431778 & 0.816540 \\
Contractor must submit a project and site specific H\&S plan for the client's & 0.451092 & 0.839142 \\
approval & 0.39103 \\
Contractor must report all lost time injuries to the client. & 0.336778 & 0.869071 \\
Contractor must report all factories Act / Workman's compensation Act & & \\
recordable injuries to the client. & 0.932957 & 0.138624 \\
Contractor must include personnel from the client in coordination meetings. & 0.898127 & 0.254158 \\
Contractor must implement a permit system when performing hazardous & & \\
activities & 0.00000 & 0.000000 \\
\hline
\end{tabular}

Table 2: A reliability analysis performed on two factors

\section{Factors 1 - Contractor Compliance}

Contractor must place at least one full-time health and safety representative on the 0.9608 project.

Contractor must provide health and safety orientation to all employees on-site. $\quad 0.9625$ Contractor must conduct pre-tender, award, and construction meetings with 0.9537 subcontractors.

Contractor must comply with the district and national health and safety regulations. $\quad 0.9494$

Contractor must submit the résumés of key health and safety personnel for client 0.9540 approval.

Contractor must include personnel from the client in coordination meetings.

Contractor must implement a permit system when performing hazardous activities

0.9551

\section{Factors 2: Contractor Recording}

Contractor must record, investigate, and report near misses to the owner 0.9526

Contractor must submit a health and safety policy signed by its CEO. 0.9568

Contractor must submit a project and site specific health and safety plan for the client's 0.9373 approval

Contractor must report all lost time injuries to the client.

Contractor must report all factories Act/Workman's compensation Act recordable 0.9338 injuries to the client.

Overall results suggest that these factors are not followed in the Botswana construction industry. This indicates that H\&S within the contract is not even a point of discussion for inclusion at the planning stage. Further results of an orthogonal rotation of the solution are shown in Table 1. The analysis yielded a twofactor solution with a simple structure seven items loaded onto Factor 1 . It is clear from Table 1 that these seven items all relate to contractor compliance of H\&S requirements to be specifically included in the construction contract. This factor indicates that the contractor must place at least one full-time H\&S representative on the project, provide H\&S orientation to all employees on-site, conduct pre-tender, award, and construction meetings with subcontractors, comply with the district and national H\&S 
regulations, submit the résumés of key H\&S personnel for client approval, include personnel from the client in coordination meetings and implement a permit system when performing hazardous activities. This factor was labelled, "Contractor Compliance". Six items load onto a factor 2 related to contractor recording of H\&S requirements specifically to be included in the construction contract. These were identified as the contractor must implement a drug-testing program, record, investigate, and report near misses to the owner, submit an H\&S policy signed by its CEO, submit a project and site specific H\&S plan for the client's approval, report all lost time injuries to the client, and report all factories Act / Workman's compensation Act recordable injuries to the client. This second factor was labelled, "Contractor recording". The Cronbach alpha coefficient using SAS was then determined for the two factors. The purpose is to measure internal consistency and the degree to which instruments items are homogeneous and reflect the same underlying construct(s). The individual alpha values of the two factors are recorded in table 3 .

The correlation between the two factors was then investigated and the results are recorded in Table 3 . The results indicate that there is a good correlation between contractor compliance and contractor recording.

Table 3: Correlation between Contractor Compliance and Contractor Recording

\begin{tabular}{llll}
\hline Correlations & $\begin{array}{l}\text { Contractor } \\
\text { Compliance }\end{array}$ & $\begin{array}{l}\text { Contractor } \\
\text { Recording }\end{array}$ & $\begin{array}{l}\text { Significant } \\
\text { Probability }\end{array}$ \\
\hline Contractor Compliance & 1.0000 & 0.7333 & \\
Contractor Recording & 0.7333 & 1.0000 & $<.0001^{*}$ \\
\hline
\end{tabular}

* $\quad$ Significance test at $p \leq 0.05$

These results indicate a significant correlation between contactor compliance and contract recording. This good correlation is further supported by the Linear Fit between the two variables, assuming that compliance predicts recording - as indicated in the figures 1.

\section{Figure 1: Bivariate fit of contractor recording by contractor compliance}

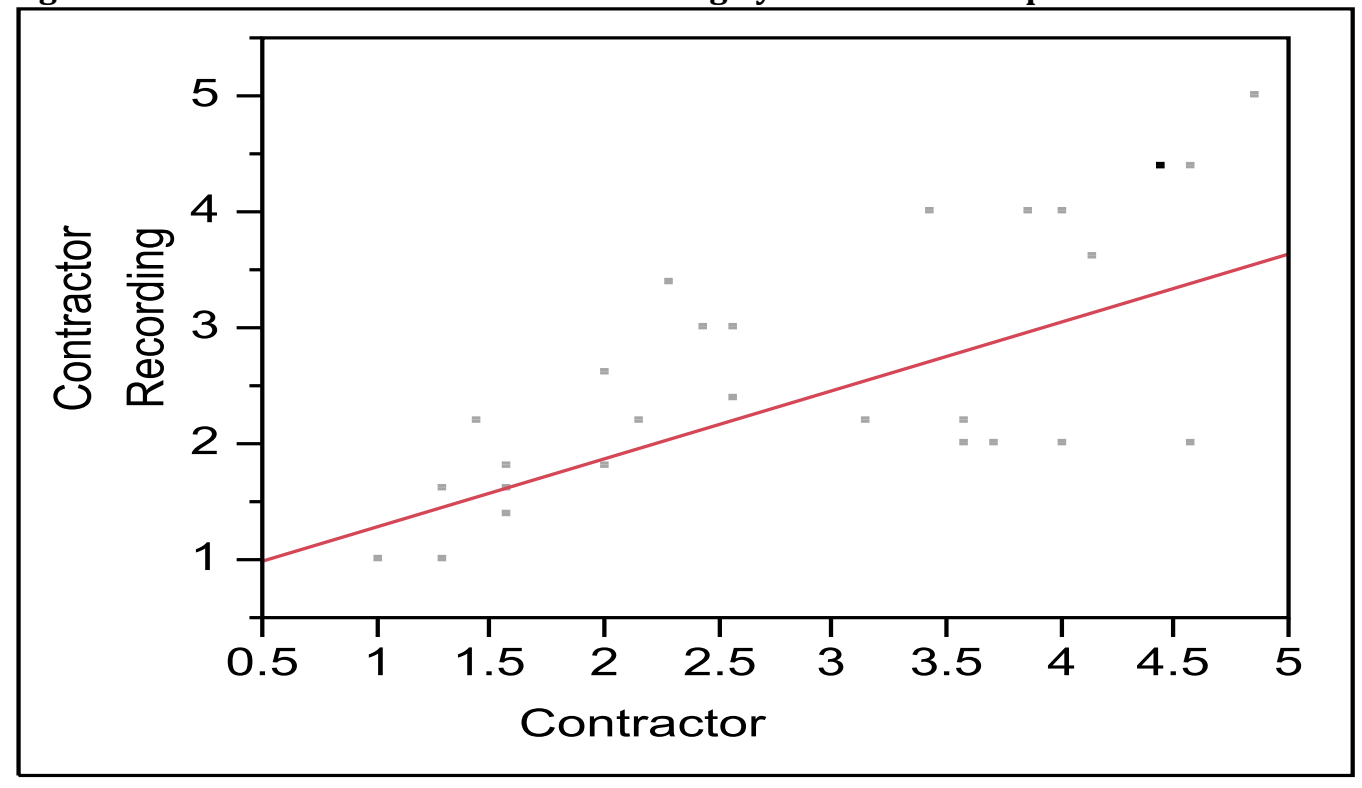

Another analysis on H\&S requirements in contracts was conducted to determine the extent of construction hazard recognition and specification of less harmful materials by the stakeholders participating in the survey. A Construction Hazard Recognition Index (CHRI) was created from the mean of the two constructs that seek to determine whether:

- Health and safety hazards were identified in the construction drawings

- The process of identifying hazards in the construction drawings was detailed

Similarly a Specification of Less Harmful Materials Index (SLHMI) was created from the mean of two 
constructs to determine whether:

- Hazardous materials are often taken into consideration when specifying materials.

- The process of determining the extent of hazard in the materials was detailed.

Correlation between the two factors, viz. (1) Construction Hazard recognitions index and (2) Specification of less harmful materials index, was then investigated and the results are recorded in table 4 .

Table 4: Correlations between Specification of Less Harmful Materials Index and Construction Hazard Recognition Index

\begin{tabular}{llll}
\hline Correlations & $\begin{array}{l}\text { Construction Hazard Specification of } \\
\text { Recognition Index }\end{array}$ & $\begin{array}{c}\text { Less Significant } \\
\text { Harmful Materials Index }\end{array}$ & Probability \\
\hline $\begin{array}{l}\text { Construction Hazard Recognition } 1.0000 \\
\text { Index }\end{array}$ & 0.5224 & \\
$\begin{array}{l}\text { Specification of Less Harmful } \\
\text { Materials Index }\end{array}$ & & 1.0000 & $<.0001^{*}$ \\
\hline
\end{tabular}

* Significance test at $p \leq 0.05$

The results in table 4 indicate a significant correlation between Specification of Less Harmful Materials Index and Construction Hazard Recognition Index. These results are further supported by the by the bivariate fit indicated in figure 2 below. This figure 2 affirms the findings in table 4 that there is a positive correlation between the two indexes (specification of less harmful materials index and construction hazard recognition index).

Figure 2: Bivariate Fit of Specification Index by Construction Recognition Index

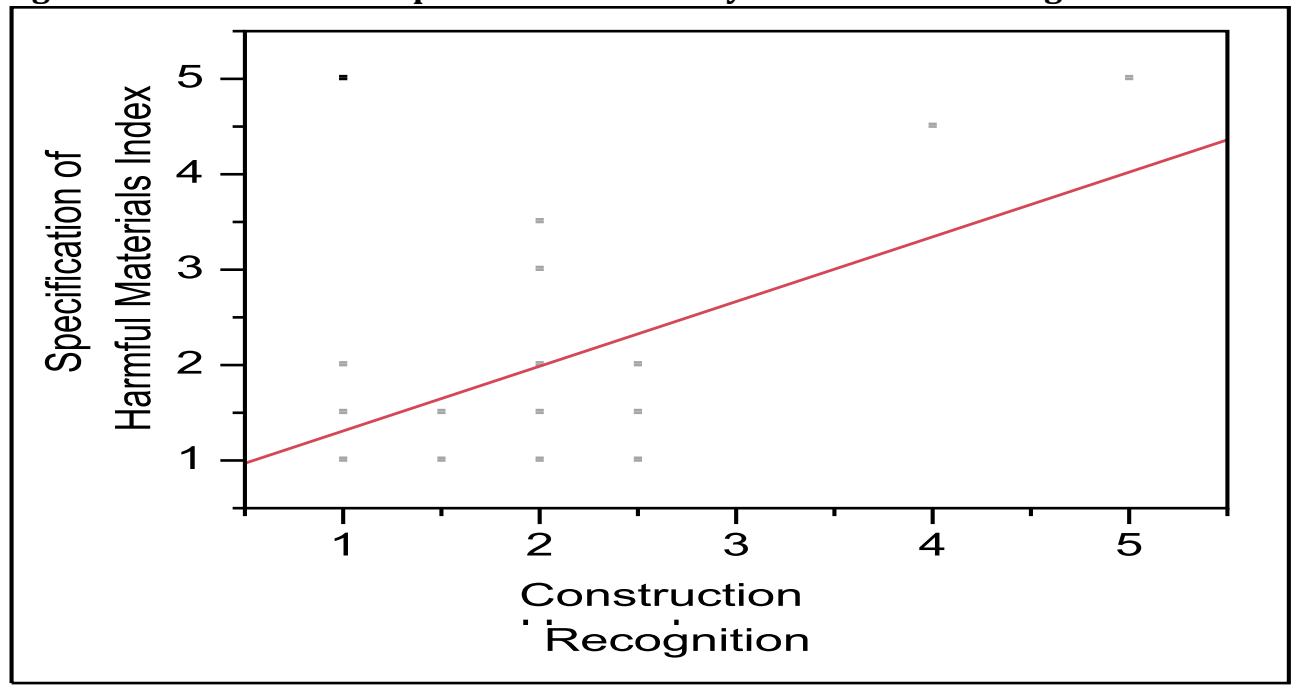

Overall results suggest that while the findings indicate a good correlation between contractor compliance and contractor recording as well as a positive correlation between the two indexes (specification of less harmful materials index and construction hazard recognition index), it is reasonable to conclude that these four factors are not practiced within the construction industry in Botswana. Further, the correlation of contractor compliance and contractor reporting of injury and hazards suggests that the difficulty of getting more consistent and higher standards of H\&S compliance may not depend only on contractual specification requirements but on systemic factors such as having mechanisms for reporting hazards, following up on hazard reports and audits, and doing what it takes to ensure that hazard reports and audits are translated into effective compliance with H\&S requirements.

Specifying health and safety compliance and reporting in the contract: The adoption of the traditional procurement method with its lowest-price culture in competitive bidding is incompatible with positive H\&S performance. However methods can be adopted where developing a process of incorporating compliance and recording process in the contract can be achieved. This would involve raising awareness for the client, designer, contractor, and for the workforce, that will put in place agreedupon mechanisms for monitoring compliance.One such mechanism, as determined from the factor 
analysis results, would be requesting the contractor to submit résumés of key H\&S personnel for client approval. This would indicate the client's interest in monitoring of compliance. According to McDonald and Hrymak (2002), the presence of H\&S representative on site is one way of identifying the strongest relationship with H\&S compliance. Other factor associated with compliance is the H\&S management factor - effectiveness of response to audits and hazard reports. Although literature has shown that there is a tendency for H\&S representatives to be present on sites with better general $\mathrm{H} \& \mathrm{~S}$ management performance, it would be a mistake to conclude that this general $\mathrm{H} \& \mathrm{~S}$ management factor accounts for the relationship between $\mathrm{H} \& \mathrm{~S}$ representatives and compliance.

McDonald and Hrymak (2002) argue that it appears that H\&S representatives influence H\&S compliance not only through their influence on the response to audits and hazards but also through other means. Thus this encourages reporting of hazards and helps ensure that these reports lead to better $\mathrm{H} \& \mathrm{~S}$ compliance on site. The presence of H\&S representatives makes it significantly less likely that the contractor and his workers will continue to work in hazardous situations.One acceptable process to enhance compliance is the selection criteria for tenders which should review the designer and contractor's previous H\&S performance and relate it to the current approach submitted during tendering. This could include not just the number of accidents but also the volume and type of past output, H\&S policy, budget, and resources; the system and structure for managing H\&S, a reporting system, including near misses and statistics on accident performance, and worker training, participation, and consultation (Murie, 2007).

It is suggested that every tender submitted should present a detailed H\&S plan before commencing work. Project-specific H\&S proposals should be required for addressing points in the tender. This should include a requirement to create and maintain the $H \& S$ file, which includes the $H \& S$ policy, risk assessments, and performance data. As the evidence shows in the finding, there is a need for capacity building not only in the area of national procurement policies, but also in capacity to implement legislative requirements and good contract compliance among clients, contractors, and designers. This requires convincing all stakeholders about the benefits of compliance. This means stakeholder workshops, training, and the availability of tools for implementation, such as good contract documents, checklists and indicators for training requirement for all stakeholders and site supervision staff to ensure that local labour laws are observed. The contract and the accompanying specifications should include a robust monitoring system, with clear roles and responsibilities. A clause in the formal contract should require the reviews of contractor compliance to be followed up in site meetings. Systemic factors are more important. These include having mechanisms for reporting hazards, following up on hazard reports and audits, and doing what it takes to ensure that hazard reports and audits are translated into effective compliance with $\mathrm{H} \& \mathrm{~S}$ requirements.As alternative means of construction procurement become more prevalent, such as partnering and design and build, the adoption of a new procurement method which brings together all key stakeholders at the conceptual stage may gain momentum.

Construction hazard recognition and specification of less harmful materials: In order to determine whether hazardous materials are often taken into consideration when specifying materials as well as whether H\&S hazards were identified in the construction drawings, respondents indicated that there was no general hazard identification carried out even from the drawings. However, there was consensus that there is a good correlation between the two factors, viz. (1) construction hazard recognitions index and (2) specification of less harmful materials index. This shows that progressive clients and designers are becoming increasingly aware that some materials are likely to offer essentially a good value and performance while at the same time providing a considerably less hazardous effect to employees. This awareness also assists in selection of materials to be specified taking into consideration $\mathrm{H} \& \mathrm{~S}$ of the people that will work with such materials.Engineers and architects typically specify materials based on perceived or experienced performance and cost (or sometimes on the basis of technical specifications of the manufacturer), rarely is that performed on the inherent $\mathrm{H} \& \mathrm{~S}$ of the materials for construction or maintenance workers. As information technology makes it easier for designers to obtain information about the inherent hazard level of various building materials, designers could be expected to apply this information by specifying less hazardous materials in their design decisions.

However, the research results suggest that designers may not yet be seeking for such information and / or manufacturers may not effectively be providing it. However, having designers who are not just aware but develop increasing interest in promoting a good H\&S performance on a project will have spill over effects on their increasing specification of materials that are less hazardous to construction workers. 
Consequently, this could lead to improved design which considers harmful materials at planning stage.Further, through stakeholder meetings and assessment of legislative framework, relevant agreements, and current site practice; it is possible to determine what risks are most important and which labour standards need to be prioritized. Harmful materials such as lead, asbestosis, silica are clearly mentioned in the workmen's compensation act and the factories act of Botswana. What designers and clients need to do is to familiarise themselves with what the current legislations say and educate themselves on how to avoid use of any harmful materials. The proposal therefore is to establish procedures for enforcement, and mechanisms for collaboration at planning stage in order to comply with existing national legislation and contractual requirements drawn by the client.

\section{Conclusion}

The study has provided useful information involving key stakeholders involvement in H\&S performance in construction industry. The results obtained indicate that both the stakeholders and the number of participants were representative of the industry practitioners of the same group taking the population of the country into consideration. The Literature was reviewed, a questionnaire survey was conducted and the statistical analysis performed to arrive at the useful information for both the study and the industry. When the traditional method of procurement is adopted, there are unclear H\&S roles for the key industry stakeholders' involved from pre planning stage through to implementation. It was not clear who would lead the H\&S management from inception of the project through design and monitoring at the implementation stage. For many developed nations, the trend was to advocate for a change of procurement method from the traditional system to partnering. The contract documentation in the construction industry in Botswana appears to refer only to the Principal Agent (usually the architect who also is provided with the brief to design), the engineer (usually the designer for civil works or structural work for building works), the quantity surveyor (to deal with project finance), and the contractor as the project implementer. Further, contract documentations only include $\mathrm{H} \& \mathrm{~S}$ as an allowance for the risk of collapse in excavations allowed for in the Bills of Quantities (BoQ). However, this item is clearly a cost component than the $\mathrm{H} \& \mathrm{~S}$ issue.

\section{References}

Hislop, R. (1999). Construction Site Safety: A Guide for Managing Contractors. Lewis Publishers, USA.

Kartam, N. A., Flood, I. \& Koushki, P. (2000). Construction safety in Kuwait: issues, procedures, problems, and recommendations. Safety Science, 36, 164-184.

Kumaraswamy, M. \& Dulaimi M. (2001). Empowering innovative improvements through creative construction procurement. Engineering Construction and Architectural Management, 8(5-6), 325334.

McDonald, N. \& Hrymak, V. (2002). Safety Behaviour in the Construction Industry. Report to the Health and Safety Authority, Dublin and the Health and Safety Executive, Northern Ireland

Murie, F. (2007). Building Safety - An International Perspective. Building and Woodworkers International (BWI), a federation of 350 trade unions. International Journal of Occupational and Environmental Health in Construction, 1(3).

Public Procurement and Asset Disposal Board (PPADB). (2008). Public Procurement and Asset Disposal Board, registration of contractors, Botswana. [on line] Available from http//www.ppadb.co.bw [Accessed on the 28th November 2008]

Rwelamila, P. D., Talukhaba, A. A. \& Ngowi, A. B. (2000). Project procurement systems in the attainment of sustainable construction. Sustainable Development, 8(1), 39-50.

Smallwood, J. (1996). The Influence of Designers on Occupational Safety and Health. In First International Conference of CIB Working Commission W99, Implementation of Safety and Health on Construction Sites, 203-213. Rotterdam: Technical University of Lisbon.

Smallwood, J. J. (2004). The influence of engineering designers on H\&S during construction. Journal of the South African Institution of civil Engineering, 46(1), 2 - 8.

Van Rijn, J. (2005). Procurement In the Construction Industry, in development countries, Edition 2005

Winch, G. M. (2000). Institutional reform in British construction: Partnering and private finance. Building Research \& Information, 28(1), 141-155. 